\title{
Indian Spices and Unhealthy Diets interfere with Drug Therapy in Diabetes and Neurodegenerative Diseases
}

\author{
Ian James Martins ${ }^{1^{*}}$ \\ ${ }^{1}$ Centre of Excellence in Alzheimer's disease Research and Care, Edith Cowan University, Australia
}

Received Date: January 10, 2018; Published Date: January 16, 2018

*Corresponding author: Ian Martins, School of Medical Sciences, Edith Cowan University, Western Australia 6009, Australia, Tel: 61863042574; Email: i.martins@ecu.edu.au

Abstract

Nutritional therapy has become important to drug metabolism and treatment with the calorie sensitive gene Sirtuin 1 (Sirt 1) shown to be critical to the prevention of non alcoholic fatty liver disease (NAFLD) with the activation of hepatic drug metabolism. Indian spices have been used extensively in healthy diets in the developing and developed countries for the prevention of NAFLD, diabetes and Alzheimer's disease. Experimental evidence with relevance to ingestion of Indian spices (mg/day) is limited in various countries. Curcumin intake (mg/ day) an amyloid beta aggregation inhibitor for the treatment of Alzheimer's disease should be carefully controlled to prevent mitophagy and NAFLD. Indian spices that contain Sirt 1 activators such as cinnamon should be consumed to maintain hepatic drug and spice metabolism with the prevention of insulin resistance. Excessive intake of various Indian spices should be avoided to maintain the therapeutic properties of curcumin and cinnamon and to prevent spice-drug or drug-drug interactions. Data on safety and toxicity of Indian spices may indicate that toxic curcumin effects may be related to over ingestion of various Indian spices relevant to drug induced mitochondrial toxicity in NAFLD, diabetes and neurodegenerative diseases.

Keywords: Indian; Spices; Drug; Curcumin; Amyloid Beta; Metabolism; Cinnamon; Sirtuin ; Nutritional Therapy; Nafld; Diabetes; Alzheimer's Disease; Mitophagy; Bacterial Lipopolysaccharides

\section{Editorial}

Healthy diets have been encouraged to reverse non alcoholic fatty liver disease (NAFLD) and accelerate hepatic drug metabolism [1] in chronic disease. Genomic medicine and nutrition have become important to drug therapy with the calorie sensitive gene Sirtuin 1 (Sirt 1) shown to be critical to the prevention of NAFLD and activation of hepatic drug metabolism [2-4]. Sirt 1 is a nicotinamide adenine dinucleotide (NAD+) dependent class III histone deacetylase (HDAC) that targets transcription factors such as p53 to adapt gene expression to metabolic activity and the deactivation of nuclear receptors indicate its critical involvement in insulin resistance [3]. Appetite control is essential to Sirt 1 and the maintenance of mitochondrial biogenesis [5] for active hepatic fat and drug metabolism [1]. Unhealthy diets that contain bacterial lipo polysaccharides (LPS) repress the anti-aging gene Sirt 1 [6] with relevance to mitophagy and decreased hepatic drug metabolism. Insulin therapy and nutritional therapy [7] are connected to the treatment of NAFLD with a healthy diet in diabetic individuals essential to prevent NAFLD and chronic disease. The health promoting benefits and protective role of Indian spices has been reported in chronic disease [8] with their role as an antioxidant and antimicrobial agent important to the prevention of NAFLD, heart disease, diabetes and Alzheimer's disease [9-14].

Consumption of spices is higher in countries such as India, China, and Thailand and there has been increased intake of Indian spices in developed countries [8]. Spice intake and its quantification (mg/day) in man has become important with the composition of spices (LPS, xenobiotics) important for risk assessment [9,15-17]. The intake of spices has been shown to vary between different countries and the geographic regions in the same country [8]. Healthy diets that activate fat and drug metabolism are important to hepatic spice metabolism with Sirt 1 activators [18] essential to maintain hepatic Indian spice metabolism and antimicrobial activation [19-21]. The metabolism of various spices from the blood plasma is poorly understood and experimental research needs to be conducted to 
determine the amount of Indian spice intake (mg/day) to prevent spice-drug interactions that may interfere with drug therapy in NAFLD and diabetes. Indian spices have been used extensively in healthy diets in the developing and developed countries for the prevention of AD. Identification of spices such as five commonly used dietary spices include saffron, curcumin, pepper family, zingiber and cinnamon [13] to inhibit amyloid beta aggregation. The curry spice curcumin has been extensively studied in animal models to reduce amyloid pathology [22] with benefiical effects on the prevention of neuro degeneration in man [23].

Information regarding curcumin bioavailability and safety in man is lacking with excessive doses associated with nausea, diarrhea, increased risk of bleeding, liver dysfunction (drug metabolism inactivation), hyperactive gallbladder contractions, hypotension (lowered blood pressure), uterine contractions/ increased menstrual flow. In the liver mitochondria play a key role in fat metabolism with Sirt 1 connected to mitochondrial biogenesis, drug metabolism and the prevention of NAFLD [17]. Currcumin is an important target for mitochondria [24] with elevated curcumin doses associated with interference with mitochondrial DNA [25] and curcumin induced cell death (Figure 1). Data on safety and toxicity of Indian spices may indicate that toxic curcumin effects may be related to ingestion of other Indian spices $[8-10,12]$ relevant to drug-drug interactions and mitochondrial toxicity [26].

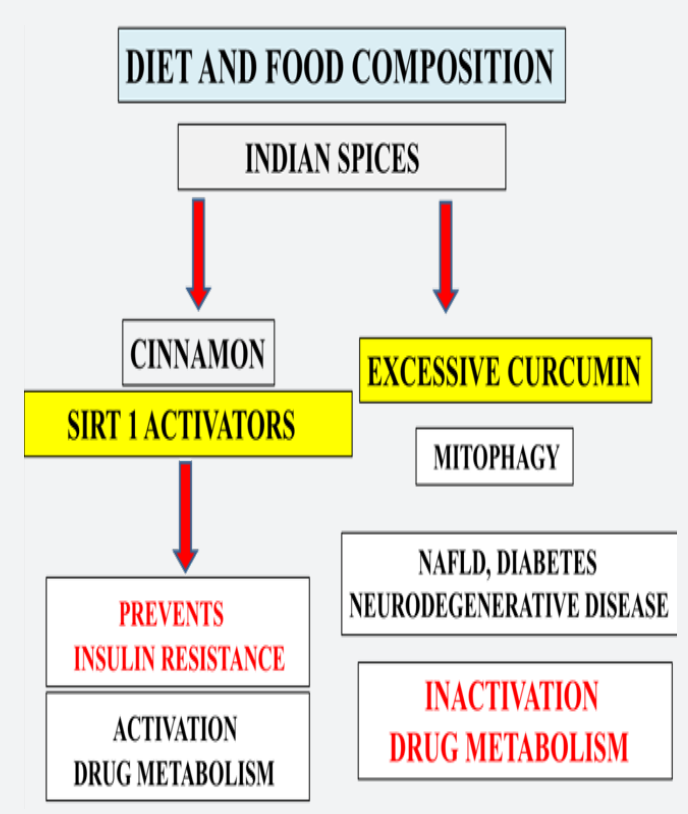

Figure 1: Healthy diets that contain curcumin should carefully control curcumin intake (mg/day) important to the prevention of amyloid beta aggregation and mitophagy. Excessive curcumin levels may induce mitophagy with relevance to NAFLD, chronic disease and inactivation of hepatic drug metabolism. Diets that contain Sirt 1 activators such as cinnamon may be important to prevent insulin resistance and maintain drug therapy and hepatic drug metabolism.
Avasimibe is a Sirt 1 activator [27] and may reduce lipophillic curcumin absorption into the blood plasma and delay its rapid sequestration by the mitochondria in various cells [28] with relevance to the months/years of curcumin consumption. Diets that contain Sirt 1 activators such as cinnamon may be important to prevent insulin resistance and maintain drug therapy and hepatic drug metabolism. In vitro and in vivo evidence suggests that cinnamon has anti-inflammatory, antimicrobial, antioxidant, immunomodulatory effects and various other health benefits [29]. Cinnamon has been reported to act an insulin mimetic and to potentaiate insulin activity. Furthermore, animal studies have demonstrated strong hypoglycemic properties. However, there are few controlled clinical studies that can be made about the potential health benefits of cinnamon in humans. Cinnamon is now been reported as a Sirt 1 activator $[29,30]$ with its role in activtation of Sirt 1 hepatic amyloid beta and drug metabolism [1].

Sirt 1 has now been reported to be the heat shock gene with its role important to heat shock protein 70 (HSP70) metabolism relevant to the inactivation of amyloid beta metabolism [31-34]. Curcumin as a Indian spice is important to prevent amyloid beta aggregation but not the HSP70 and amyloid beta interaction that is relevant to endoplasmic reticulum stress with relevance to drug toxicity $[34,35]$. Caffeine is a Sirt 1 modulator and important with relevance to hepatic drug metabolism [36,37] and brain regulation of amyloid beta metabolism relevant to Alzheimer's disease and neurodegenerative disease [1]. Indian spice consumption (mg/day) over years should be carefully calculated to prevent interference with caffeine Sirt 1 modulation with relevance to the rapid brain to liver amyloid beta transport [37]. Information with relevance to Indian spice transport to cells in the brain with relevance to overingestion or defective blood plasma spice metabolism is not available with excessive Indian spice contents in the brain relevant to amyloid beta aggregation and mitophagy.

\section{Conclusion}

Experimental evidence with relevance to ingestion of Indian spices ( $\mathrm{mg} /$ day) is limited in various countries. Dietary fat may determine curcumin intake (mg/day) (amyloid beta aggregation inhibitor) for the prevention of mitophagy, NAFLD and the treatment of Alzheimer's disease. Sirt 1 activators should be consumed to maintainhepatic fat, curcumin anddrug metabolism with the prevention of insulin resistance.Excessive intake of various Indian spices should be avoided to maintain the therapeutic properties of curcumin and cinnamon and to prevent spice-drug or drug-drug interactions. In vitro and in vivo evidence is required with relevance to the blood plasma/ liver clearance rates of Indian spices with relevance to hepatic drug inactivation and drug metabolism.

Acknowledgement 


\section{Novel Approaches in Drug Designing \& Development}

This work was supported by grants from Edith Cowan University, the McCusker Alzheimer's Research Foundation and the National Health and Medical Research Council.

\section{References}

1. Martins IJ (2017) Inactivation of Anti-Aging Genes is Related to Defective Drug Metabolism in Diabetes. Int J Drug Disc 1: 003.

2. Martins IJ (2014) Induction of NAFLD with Increased Risk of Obesity and Chronic Diseases in Developed Countries. OJEMD 4(4): 90-110.

3. Martins IJ (2015) Unhealthy Nutrigenomic Diets Accelerate NAFLD and Adiposity in Global communities. J Mol Genet Med 9: 1-11.

4. Martins IJ (2015) Overnutrition Determines LPS Regulation of Mycotoxin Induced Neurotoxicity in Neurodegenerative Diseases. Int J Mol Sci 16(12): 29554-29573.

5. Martins IJ (2016) Appetite Control with Relevance to Mitochondrial Biogenesis and Activation of Post- Prandial Lipid Metabolism in Obesity Linked Diabetes. Ann Obes Disord 1(3): 1012.

6. Martins IJ (2017) The Future of Genomic Medicine Involves the Maintenance of Sirtuin 1 in Global Populations. Int J Mol Biol 2(1): 00013.

7. Martins IJ (2017) Insulin Therapy Inactivation is connected to NAFLD and Diabetes Severity Index. J Diab Clin Stud 1(1): 001-003.

8. Siruguri V, Bhat RV (2015) Assessing intake of spices by pattern of spice use, frequency of consumption and portion size of spices consumed from routinely prepared dishes in southern India. Nutr J 14(7): $1-9$.

9. Rawat S, Rawat A (2015) Antimicrobial activity of Indian spices against pathogenic bacteria. Adv Appl Sci Res 6(3): 185-190.

10. Modak M, Dixit P, Londhe J, Ghaskadbi S, Devasagayam TPA (2007) Indian Herbs and Herbal Drugs Used for the Treatment of Diabetes. J Clin Biochem Nutr 40(3): 163-173.

11. Suriyavathana Vedanarayanan M, Krishnan N (2011) Ayurvedic formulation of Liv-Pro-08 reduces nonalcoholic fatty liver disease in rats fed with high-fat diet. J Acupunct Meridian Stud 4(4): 236-241.

12. Vasanthi HR, Parameswari RP (2010) Indian Spices for Healthy HeartAn Overview. Curr Cardiol Rev 6(4): 274-279.

13. Mirmosayyeb O, Tanhaei A, Sohrabi HR, Martins RN, Tanhaei M, et al (2017) Possible Role of Common Spices as a Preventive and Therapeutic Agent for Alzheimer's Disease. Int J Prev Med 8: 5.

14. Krishnaswamy K (2008) Traditional Indian spices and their health significance. Asia Pac J Clin Nutr 17(1): 265-268.

15. Al Mofleh IA (2010) Spices, herbal xenobiotics and the stomach: Friends or foes? World J Gastroenterol 16(22): 2710-2719.

16. Chowdhury R, Nimmanapalli, R, Graham T, Reddy G (2013) Curcumin Attenuation of Lipopolysaccharide Induced Cardiac Hypertrophy in Rodents. ISRN Inflamm 2013: 8.

17. Martins IJ (2013) Increased Risk for Obesity and Diabetes with Neurodegeneration in Developing Countries. J Molecular Genet Medi 1:1-8,

18. Martins IJ (2017) Nutrition Therapy Regulates Caffeine Metabolism with Relevance to NAFLD and Induction of Type 3 Diabetes. J Diabetes Metab Disord 4: 1-9.
19. Martins IJ (2017) Antibiotic Resistance Involves Antimicrobial Inactivation in Global Communities. SAJ Pharma Pharmacol 2: 102.

20. Martins IJ (2017) Antimicrobial activity inactivation and toxic immune reactions induce Epilepsy in human. J Med Discov 2(4): 1-7.

21. Martins IJ (2018) Antimicrobial Drugs and Bacterial Amyloid Peptide Induce Toxic Manifestations in Chronic Diseases. ECPT 6(1): 01-04.

22. Ringman JR, Frautschy SA, Cole GM, Masterman DL,Cummings JL (2005) A Potential Role of the Curry Spice Curcumin in Alzheimer's Disease. Curr Alzheimer Res 2(2): 131-136.

23. Mishra S, Palanivelu K (2008) The effect of curcumin (turmeric) on Alzheimer's disease: An overview. Ann Indian Acad Neurol 11(1): 13-19.

24. Trujillo J, Granados-Castro LF, Zazueta C, Andérica-Romero AC, Chirino YI, et al (2014) Mitochondria as a target in the therapeutic properties of curcumin. Arch Pharm (Weinheim). 347(12): 873-884.

25. Cao J, Jia L, Zhou HM, Liu Y, Zhong LF (2006) Mitochondrial and nuclear DNA damage induced by curcumin in human hepatoma G2 cells. Toxicol Sci 91(2):476-483.

26. Martins IJ (2017) Drug-Drug Interactions with Relevance to Drug Induced Mitochondrial Toxicity and Accelerated Global Chronic Diseases. ЕСРТ 3(1): 18-21.

27. Martins IJ (2017) Avasimibe and Sirt 1 Activators Reverse NAFLD and Obesity. Nov Appro Drug Des Dev 1(3): 555561.

28. Pawar YB, Munjal B, Arora S, Karwa M, Kohli G, et al (2012) Bioavailability of a Lipidic Formulation of Curcumin in Healthy Human Volunteers. Pharmaceutics 4(4): 517-530.

29. Gruenwald J, Freder J, Armbruester N (2010) Cinnamon and health. Crit Rev Food Sci Nutr 50(9): 822-34.

30. Brennemen M, Mahfouz T, Stockert A (2017) Cooperative binding of cinnamon polyphenols as activators of Sirtuin-1 protein in the insulin signaling pathway. The FASEB Journal 31(1): 761-725.

31. Qin B, Panickar KS, Anderson RA (2014) Cinnamon polyphenols regulate $\mathrm{S} 100 \boldsymbol{\beta}$, sirtuins, and neuroactive proteins in rat C6 glioma cells. Nutrition 30(2): 210-217.

32. Martins IJ (2016) Type 3 diabetes with links to NAFLD and Other Chronic Diseasesin the Western World. Int J Diab 1: 1-5.

33. Martins IJ (2016) Heat shock gene Sirtuin 1 regulates post-prandial lipid metabolism with relevance to nutrition and appetite regulation in diabetes. International Journal of Diabetes and Clinical Diagnosis. Int ] Diab Clin Diagn 3: 20.

34. Martins IJ (2017) Calorie Sensitive Anti-Aging Gene Regulates Hepatic Amyloid Beta Clearance in Diabetes and Neurodegenerative Diseases. EC Nutrition ECO 01: 30-32.

35. Martins IJ (2017) Heat Shock Gene Dysregulation and Inactivation of Drug Therapy. ECPT ECO 01: 13-15.

36. Martins IJ (2017) Caffeine with Links to NAFLD and Accelerated Brain Aging. Chapter: Non-Alcoholic Fatty Liver Disease - Molecular Bases, Prevention and Treatment. In Tech-Open Science Open Minds | In Tech Open.

37. Martins IJ (2016) Caffeine consumption with Relevance to Type 3 diabetes and accelerated brain aging. Research and Reveiws: Neuroscience 1(1): 1-5. 
This work is licensed under Creative Commons Attribution 4.0 License DOI: $10.19080 / N A P D D .2018 .03 .555616$
Your next submission with Juniper Publishers will reach you the below assets

- Quality Editorial service

- Swift Peer Review

- Reprints availability

- E-prints Service

- Manuscript Podcast for convenient understanding

- Global attainment for your research

- Manuscript accessibility in different formats ( Pdf, E-pub, Full Text, Audio)

- Unceasing customer service

Track the below URL for one-step submission https://juniperpublishers.com/online-submission.php 